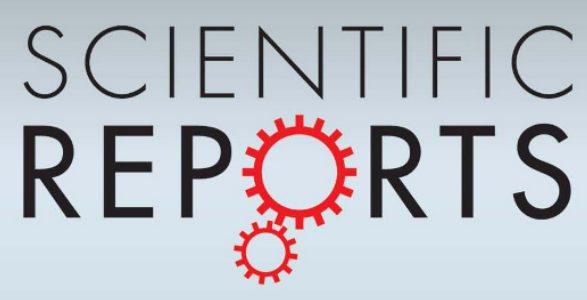

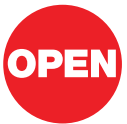

SUBJECT AREAS:

LIPIDS

METABOLOMICS

PROTEOMICS

MEDICAL RESEARCH

Received

29 July 2011

Accepted

11 October 2011

Published

7 November 2011

Correspondence and requests for materials should be addressed to

F.R. (F.Rezaee@amc.uva.nl or F.Rezaee@umcg.nl)

\section{A Phospholipidomic Analysis of All Defined Human Plasma Lipoproteins}

\author{
Monireh Dashti', Willem Kulik², Frans Hoek ${ }^{3}$, Enno C. Veerman ${ }^{4}$, Maikel P. Peppelenbosch ${ }^{1,5}$ \\ \& Farhad Rezaee ${ }^{1,6}$
}

\begin{abstract}
'Department of Cell Biology, University Medical Center Groningen, University of Groningen, Groningen, The Netherlands, ${ }^{2}$ Laboratory Genetic Metabolic Diseases, ${ }^{3}$ Department of Clinical Chemistry, Academic Medical Center, University of Amsterdam, Amsterdam, The Netherlands, ${ }^{4}$ Department of Dental Basic Sciences, Section of Oral Biochemistry, Academic Centre for Dentistry Amsterdam (ACTA), VUMC, Amsterdam, The Netherlands, ${ }^{5}$ Department of Gastroenterology and Hepatology, Erasmus Medical Center, Rotterdam, The Netherlands, ${ }^{6}$ Department for Experimental and Molecular Medicine, Academic Medical Center, University of Amsterdam, Amsterdam, The Netherlands.
\end{abstract}

Since plasma lipoproteins contain both protein and phospholipid components, either may be involved in processes such as atherosclerosis. In this study the identification of plasma lipoprotein-associated phospholipids, which is essential for understanding these processes at the molecular level, are performed. LC-ESI/MS, LC-ESI-MS/MS and High Performance Thin Layer Chromatography (HPTLC) analysis of different lipoprotein fractions collected from pooled plasma revealed the presence of phosphatidylethanolamine (PE), phosphatidylinositol (PI), and sphingomyeline (SM) only on lipoproteins and phosphatidylcholine (PC), Lyso-PC on both lipoproteins and plasma lipoprotein free fraction (PLFF). Cardiolipin, phosphatidylglycerol (PG) and Phosphatidylserine (PS) were observed neither in the lipoprotein fractions nor in PLFF. All three approaches led to the same results regarding phospholipids occurrence in plasma lipoproteins and PLFF. A high abundancy of PE and SM was observed in VLDL and LDL fractions respectively. This study provides for the first time the knowledge about the phospholipid composition of all defined plasma lipoproteins.

D espite major advances in the aetiology, prevention and treatment of cardiovascular disease, and in particular atherosclerosis, it remains the leading cause of mortality and morbidity in Western countries. Atherosclerosis results from the interaction between genetic and environmental factors modulating the functions of various cell types and inflammatory molecules within the arterial wall ${ }^{1,2}$. Extensive epidemiological studies have shown that lipoproteins play a major role in atherosclerosis of which LDL cholesterol levels are directly related to the risk of coronary artery disease and HDL cholesterol levels are inversely related to this risk ${ }^{3}$. Despite lipid cholesterol modification therapies such as LDL-lowering treatments, cardiovascular events still occur. In addition, compared to plasma cholesterol measurements, much less attention has been given to the relationship between phospholipids and atherosclerosis.

Lipoproteins are different in phospholipid composition and (apolipo) protein contents ${ }^{4-6}$. Moreover, the apolipoproteins play an important role in lipoprotein stability, binding, and catabolism ${ }^{7}$. In addition, plasma phospholipids transfer protein (PLTP) mediates the transfer of phospholipids from VLDL and LDL to HDL and is able to modulate HDL size and composition and may also be involved in HDL cellular-mediated efflux of phospholipids and cholesterol ${ }^{8-11}$. The presence of abnormal phospholipids was also shown in patients with essential hypertension ${ }^{12}$. In addition, it was recently shown that the phospholipid composition of HDL plays an important role in SR-BI- and ABCA1-mediated cholesterol efflux ${ }^{13,14}$. Yancey et al. ${ }^{14}$ also demonstrated that Phosphatidylcholine (PC) enrichment of HDL increase the efflux, whereas sphingomyelin decrease the influx of HDL cholesterol. Other studies suggest that the phospholipid composition of HDL could be a key determinant in a variety of other processes, including the inhibition of adhesion molecules, ${ }^{15-18}$ the efflux of cholesterol from Fu5AH cells to human serum ${ }^{19}$ and in its anti-inflammatory and anti-oxidant properties ${ }^{20,21}$.

It is also recently suggested that hemodialysis therapy in patients with chronic renal failure play an important role in dyslipidemic profile of these patients by modification of lipid and phospholipids composition concentrations $^{22}$. Furthermore, it has been recently reported that the concentrations of phospholipid composition are clearly different in acute phase HDL compared to normal HDL ${ }^{23}$.

The phospholipid content is one of the factors, which have been suggested to contribute to the closer lateral molecular packing in $\mathrm{LDL}^{24}$. The phospholipid composition in surface of lipoprotein particles influences the binding of apo A-I and that is the reason why apo A-I is absent in LDL particles in vivo ${ }^{24}$. The impairment of PC biosynthesis led to the inhibition of VLDL secretion, ${ }^{25}$ resulting in the changing of nascent VLDL phospholipids 
contents ${ }^{26}$. In addition, VLDL stimulates the contact pathway of blood coagulation via the exposure of phosphatidylethanolamine ${ }^{27}$. Navab et al. ${ }^{28}$ have recently shown that oral phospholipid 1,2-dimyristoyl-sn-glycero-3-phosphocholine (DMPC) in the drinking water of apoE-deficient mice results in an increase of plasma HDL cholesterol levels, an improvement in HDL function, and a marked reduction in atherosclerosis. Moreover, numerous studies have shown that phospholipid administration leads to the reduction of atherosclerotic development in vivo ${ }^{29-31}$.

Based on above-mentioned evidence, plasma lipoproteins contain both protein and phospholipid components, either of which may be involved in the atherosclerosis, inflammation, lipid metabolism, and haemostatic processes. Thus, the plasma lipoprotein functions can be manipulated by protein or phospholipids compositions.

After genomics and proteomics, many analytical techniques have been developed and used to elucidate the human lipidome. A lipidomics approach may be a reliable way to analyze the lipid composition in biological fluids, such as human plasma lipoproteins. A reliable analysis of phospholipid molecules, "lipidomics", in the context of genomics and proteomics is an essential step to understanding cellular physiology and pathology and consequently, lipid biology has become a major research target of the post-genomic revolution and systems biology.

In our previous study, we have characterized proteins associated with $\mathrm{HDL}^{32}$. In this study, liquid chromatography-electrospray ionization/mass spectrometry (LC-ESI-MS) and tandem MS were performed to identify the phospholipids composition of the major lipoprotein classes. ESI allows for large, non-volatile molecules to be analyzed directly from the liquid phase. The analysis of main phospholipids composition of lipoproteins is needed to gain additional insight into in vivo functions of lipoprotein-phospholipids content both in normal and pathological states.

\section{Results}

Characterization of lipoproteins. High performance gel-permeation chromatography (HPGC). To investigate whether one-step ultracentrifugation provided lipoprotein fractions of acceptable purity, the collected lipoprotein fractions were subjected to HPGC (figure 1). The HDL fraction obtained by ultracentrifugation resulted in a single peak with a retention time of approximately $51 \mathrm{~min}$ (figure 1D).
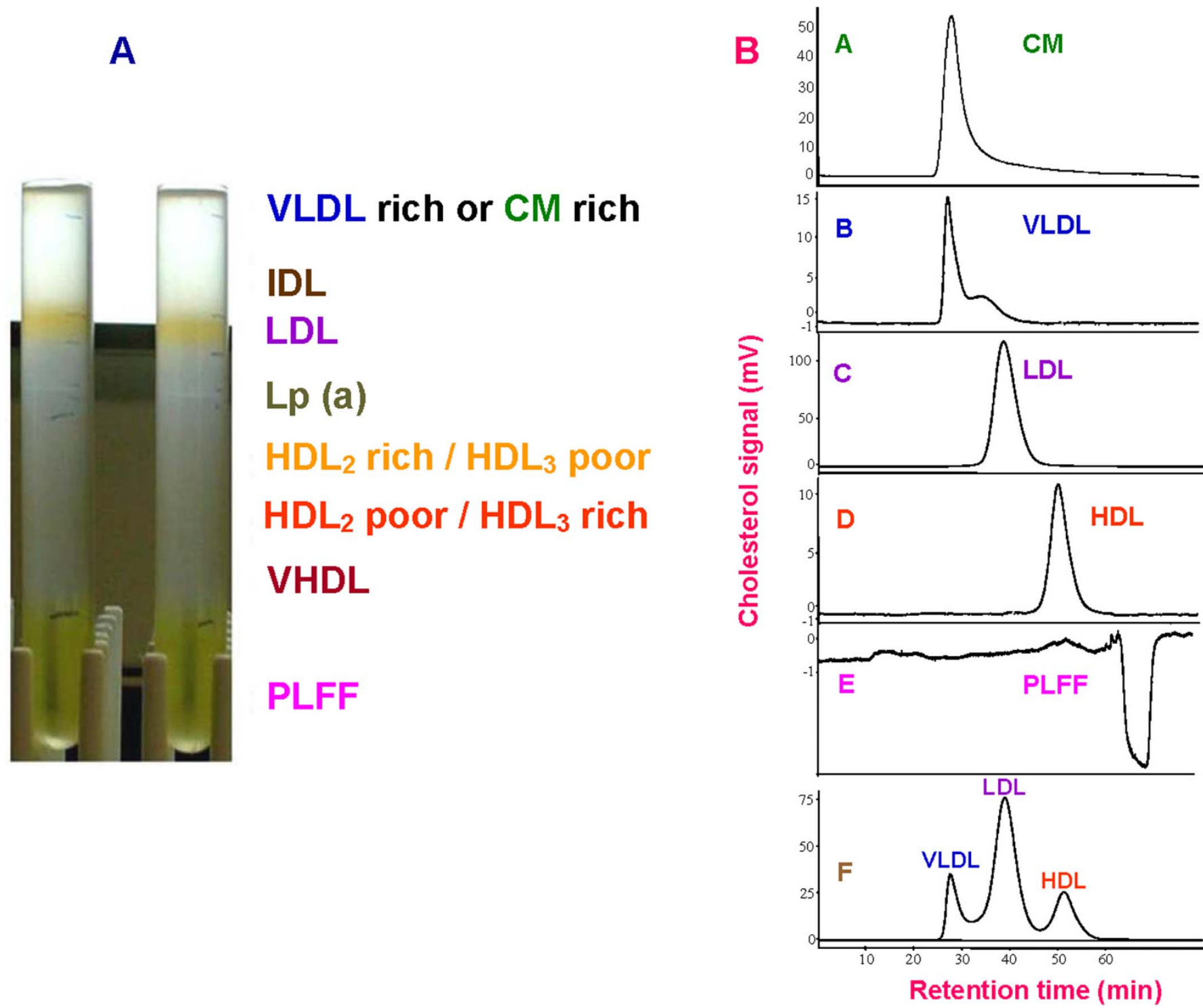

Figure $1 \mid$ Panel A shows the major human plasma lipoprotein fractions after one-step salt gradient ultracentrifugation. Panel B shows Cholesterol profiles of major plasma lipoprotein fractions separated by High Performance Gel-Permeation Chromatography (HPGC). Lipoprotein fractions obtained by one-step ultracentrifugation were subjected to size-exclusion chromatography as described in Material and Methods. Panel (A) CM fraction, Panel (B) VLDL fraction, panel (C) LDL fraction, panel (D) HDL fraction, panel E: Plasma lipoproteins free fraction and panel F: standard cholesterol. 


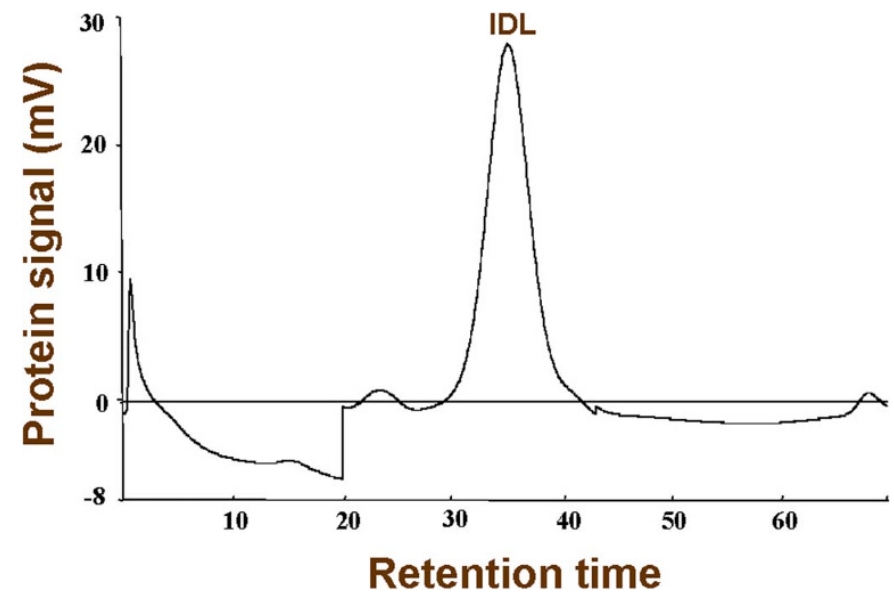

Figure $2 \mid$ Protein profile of IDL fraction. The ultra collected IDL fraction were several times exposed to HPGC to purify the IDL, therefore we used protein profile (to re-use elution for HPGC exposure) instead of cholesterol profile as described in Material and Methods. However, the cholesterol profile of ultra collected IDL fraction (before purification with HPGC) revealed approximately the same elution peak.

HPGC elution of a commercial HDL lipoprotein standard revealed identical elution patterns, which confirmed that the fraction contained only HDL (figure 1F). VLDL and LDL fractions isolated by the same method yielded peaks eluting at approximately $28 \mathrm{~min}$ and $40 \mathrm{~min}$, respectively (figure $1 \mathrm{~B}$ and $\mathrm{C}$ ). Same retention times were found when commercial LDL and VLDL lipoprotein standards were analyzed by HPGC, confirming the identity of the peaks (figure 1F). However, the intermediate-density lipoprotein (IDL) peak was also detected in the VLDL fraction. No peaks were detected in the plasma lipoprotein free fraction (figure 1E). The IDL fraction obtained by a combination of ultracentrifugation and HPGS yielded a peak eluting at approximately $35 \mathrm{~min}$ (figure 2). Although the IDL fraction contains LDL, the fraction was very highly enriched in IDL. The subjection of CM fraction to HPGC resulted in a single peak with a retention time of $28 \mathrm{~min}$ which is similar to elution peak of VLDL (figure 1A). Although both CM and VLDL fractions yielded a peak eluting at $28 \mathrm{~min}$, the IDL peak was not observed in CM fraction.

Nephlometry and Western blot analysis of apolipoproteins. Nephelometry was performed to further investigate the results obtained by HPGC concerning the purity of the isolated lipoprotein fractions collected by ultracentrifugation. Nephelometric analysis revealed the presence of apo A-I in the HDL fraction (approximately $1.1 \mathrm{~g} / \mathrm{l}$ ), but not in the VLDL, IDL and LDL or plasma lipoprotein free fractions. In addition, no cross-contamination of apo B was observed in the HDL or PLFF fractions while it was found to be abundant in the CM $(0.52 \mathrm{~g} / \mathrm{l})$,

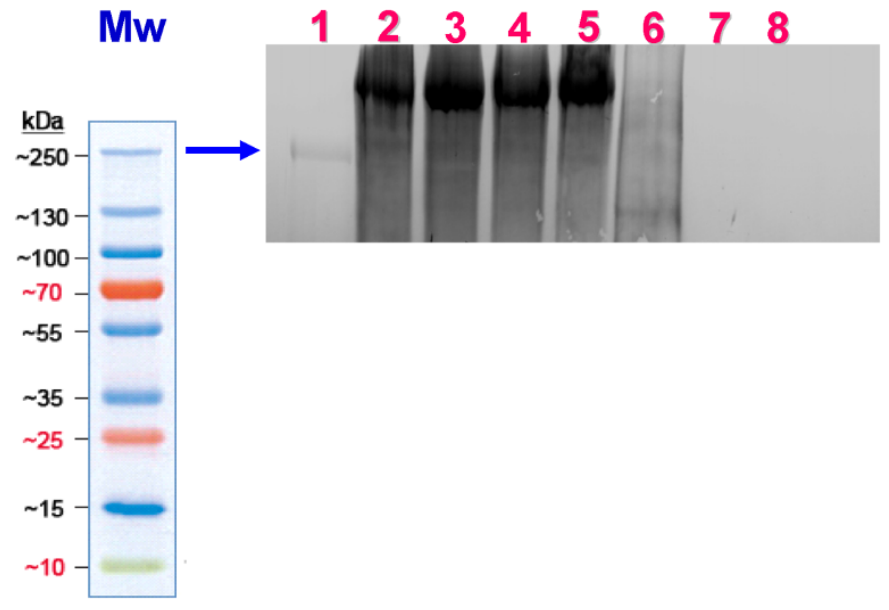

Figure 3 Western blot analysis of purified plasma lipoproteins. Plasma lipoprotein- associated proteins $(20-100 \mu \mathrm{g})$ were separated by $6 \%(\mathrm{w} / \mathrm{v})$ SDS-PAGE under denatured conditions, blotted for $20 \mathrm{~h}$ and probed with monoclonal anti-apo B antibodies as described in Materials and Methods. The plasma lipoproteins used were CM (lane 2, $80 \mathrm{ug}$ ), VLDL (lane 3, $80 \mathrm{ug}$ ), IDL (lane 4, $80 \mathrm{ug}$ ), LDL (lane 5, $80 \mathrm{ug}$ ), Apo B protein (lane 6, $20 \mathrm{ug}$ ), and HDL (lane 7, $100 \mathrm{ug}$ ). The lane 1 is protein marker and lane 8 is plasma lipoprotein free fraction (PLFF, $100 \mathrm{ug}$ ). The molecular weight standards $\left(\mathrm{M}_{\mathrm{w}}\right)$ are in kilo Daltons $(\mathrm{kDa})$ and indicated on the left of the figure. The approximately $500 \mathrm{kDa}$ band is indicated by arrow on the left of the figure.

VLDL (approximately $0.7 \mathrm{~g} / \mathrm{l})$, IDL (0.7 g/l) and LDL (1.2 g/l) fractions. Western blotting with anti-apo $\mathrm{B}$ antibodies confirmed the results obtained by HPGC and nephlometry (figure 3). As depicted in figure 3, anti-apo B antibodies showed the presence of an intense band of about $550 \mathrm{kDa}$ corresponding to full length apo B100 in VLDL, IDL and LDL fractions, but not in HDL and PLFF fractions. This indicated that the one-step ultracentrifugation protocol resulted in a purification of the major lipoprotein fractions (and a combination of ultra and HPGC for IDL purification) without contamination with other lipoproteins.

Identification of plasma lipoprotein phospholipids composition. Liquid Chromatography-ElectroSpray Ionization-Mass Spectrometry (LC-ESI-MS). LC-ESI-MS analysis in the negative and positive mode led to the identification of different phospholipids associated with lipoproteins. All samples were run twice in positive ion and negative mode, allowing the detection of the predominant positive and/or negative ions of each class of phospholipids. Although we did not observe CL, PG and PS in all lipoprotein fractions as well as PLFF (table 1, supplement) the PI (figure $1 \mathrm{~A}-\mathrm{D}$, supplement) and SM were only detected in the plasma lipoprotein fractions (figure 2 A-

Table 1 | Relative quantitative analysis of major phospholipids in 8 plasma lipoprotein fractions as well as in novel plasma lipoprotein free fraction as plasma control based on the concentration of phospholipids used in standard mixture and expressed in $\mathrm{nmol} / \mathrm{ml}$. Plasma lipoprotein phospholipids composition and PLFF fraction were extracted and applied to one-dimensional, horizontal HPTLC as described under Materials and Methods and legend of figure 9. Samples were numbered from 1 to 9. Samples were: (1-Chylomicrons, 2-VLDL, 3-IDL, 4-LDL, 5- $\mathrm{HDL}_{2}$, 6-PLFF (Control), 7-Lp(a), 8- $\mathrm{HDL}_{3}$ and 9-VHDL. The concentration was expressed as $\mathrm{nmol} / \mathrm{ml}$. Molecular weight is abbreviated as $M W$ and expressed as kilodalton $(\mathrm{kDa})$.

\begin{tabular}{|c|c|c|c|c|c|c|c|c|c|c|}
\hline PL & 1 & 2 & 3 & 4 & 5 & 6 & 7 & 8 & 9 & $M W(D a)$ \\
\hline $\begin{array}{l}\text { L-PC } \\
\text { SM } \\
\text { PC } \\
\text { PI } \\
\text { PE }\end{array}$ & $\begin{array}{c}116 \\
719 \\
3803 \\
68 \\
164\end{array}$ & $\begin{array}{c}17 \\
173 \\
1080 \\
22 \\
64\end{array}$ & $\begin{array}{c}5 \\
72 \\
180 \\
6 \\
6\end{array}$ & $\begin{array}{c}53 \\
1258 \\
6022 \\
97 \\
189\end{array}$ & $\begin{array}{c}110 \\
891 \\
230772 \\
298 \\
633\end{array}$ & $\begin{array}{c}63 \\
5 \\
61 \\
0 \\
0\end{array}$ & $\begin{array}{c}0 \\
71 \\
236 \\
0 \\
0\end{array}$ & $\begin{array}{c}20 \\
247 \\
3144 \\
38 \\
96\end{array}$ & $\begin{array}{c}51 \\
65 \\
561 \\
14 \\
26\end{array}$ & $\begin{array}{l}525 \\
747 \\
791 \\
867 \\
748\end{array}$ \\
\hline
\end{tabular}

Samples (1-9) concentration (nmol/ml). 
$\mathrm{D}$, supplement). The PC, Lyso-PC and PE were also detected in all fractions (table 1, supplement,). However, PE was not measured in PLFF fraction, using LC-ESI-MS approach (see Materials and Methods; ESI-MS paragraph). Also, CM was not analyzed by LCESI-MS strategy.

LC-ESI-tandem MS (LC-ESI-MS/MS). LC-ESI-MS/MS was applied to further examine the observed phospholipild profile in the major lipoprotein fractions and PLFF obtained by LC-ESI-MS analysis.

LC-ESI-MS/MS strategy revealed the presence of PE (figure 4 $\mathrm{A}-\mathrm{E}$ ), PI (figure $5 \mathrm{~A}-\mathrm{E}$ ) and $\mathrm{SM}$ (figure $6 \mathrm{~A}-\mathrm{E}$ ) in all lipoprotein fractions but not in PLFF. The occurrence of PC and Lyso-PC were shown in all lipoprotein fractions and PLFF (figure $7 \mathrm{~A}-\mathrm{E}$ and figure 8 A-E respectively), using LC-ESI-MS/MS. Although traces of SM were found in PLFF fraction, it could have resulted from very small traces of VHDL fraction and not vice versa. Furthermore, the CL, PG, and PS were also not detected in all fractions, applying this strategy. Although CL, PG, and PS were not observed in all fractions, lipoprotein fractions and PLFF obtained by LC-ESI-MS/MS strategy corresponded with the LC-ESI-MS profiles of the same fractions. The global intensity of each analyzed phospholipid in the different fractions was shown in table 1.
High Performance Thin Layer Chromatography (HPTLC). HPTLC was performed to further confirm the results obtained by MS and tandem MS. The relative abundance of plasma lipoprotein-associated phospholipids as determined by LC-ESI-MS and LC- ESI- tandem MS method agrees very well with those results obtained by HPTLC approach (figure 9). HPTLC method also confirmed the presence of PE, PI and SM only in lipoprotein fractions and not in PLFF fraction (figure 9). Moreover, as depicted in figure $9 \mathrm{CL}, \mathrm{PG}$, and PS were not detected in all fractions applying HPTLC and corresponded to the results obtained either by LC-ESI-MS or LC- ESI-MS/MS (tandem MS). Similar results were also obtained by HPTLC as compared to the other two above-mentioned strategies regarding PC and Lyso-PC (MS data of HDL-2 and VHDL not shown). Although HPTLC confirmed the results obtained by two other strategies, the relative quantity of the major phospholipids was calculated and shown in table 2. As displayed in table 2, the relative concentration of PC in HDL2 was tremendously higher than the rest of plasma lipoproteins.

\section{Discussion}

To shed light in the role of lipoproteins in patho-physiologic processes it is essential to elucidate the make-up of the lipoprotein particles, i.e. its phospholipid and protein composition. Since recent
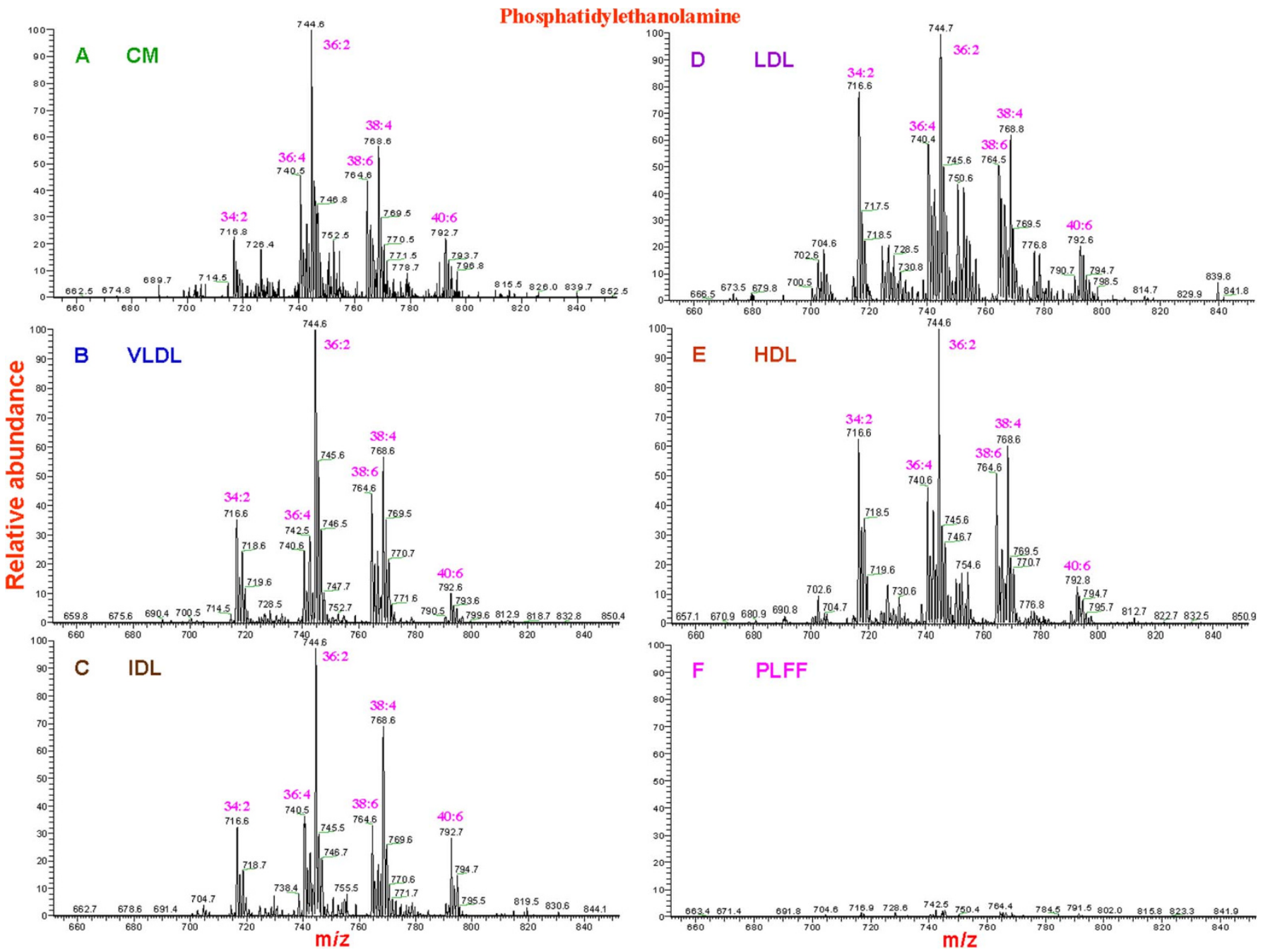

Figure 4 | High-performance liquid chromatography electrospray ionization tandem mass spectrometry analysis of plasma lipoproteins and plasma lipoprotein free fraction. We did not observe any adducts ions like $\mathrm{Na}$ or $\mathrm{K}$. positive scan $[\mathrm{M}+\mathrm{H}]+$. Characteristic part of the parent-scan for phosphatidylethanolamine (PE) in the corresponding retention time window. '36:2' specifies the composition of the protonated molecular ion as a species with $36 \mathrm{C}$-atoms in total in the acyl-chains with 2 unsaturated bonds in total; other assignments are analogous. (A) CM fraction, (B) VLDL fraction, (C) IDL fraction, (D) LDL fraction, (E) HDL fraction and (F) PLFF fraction. 

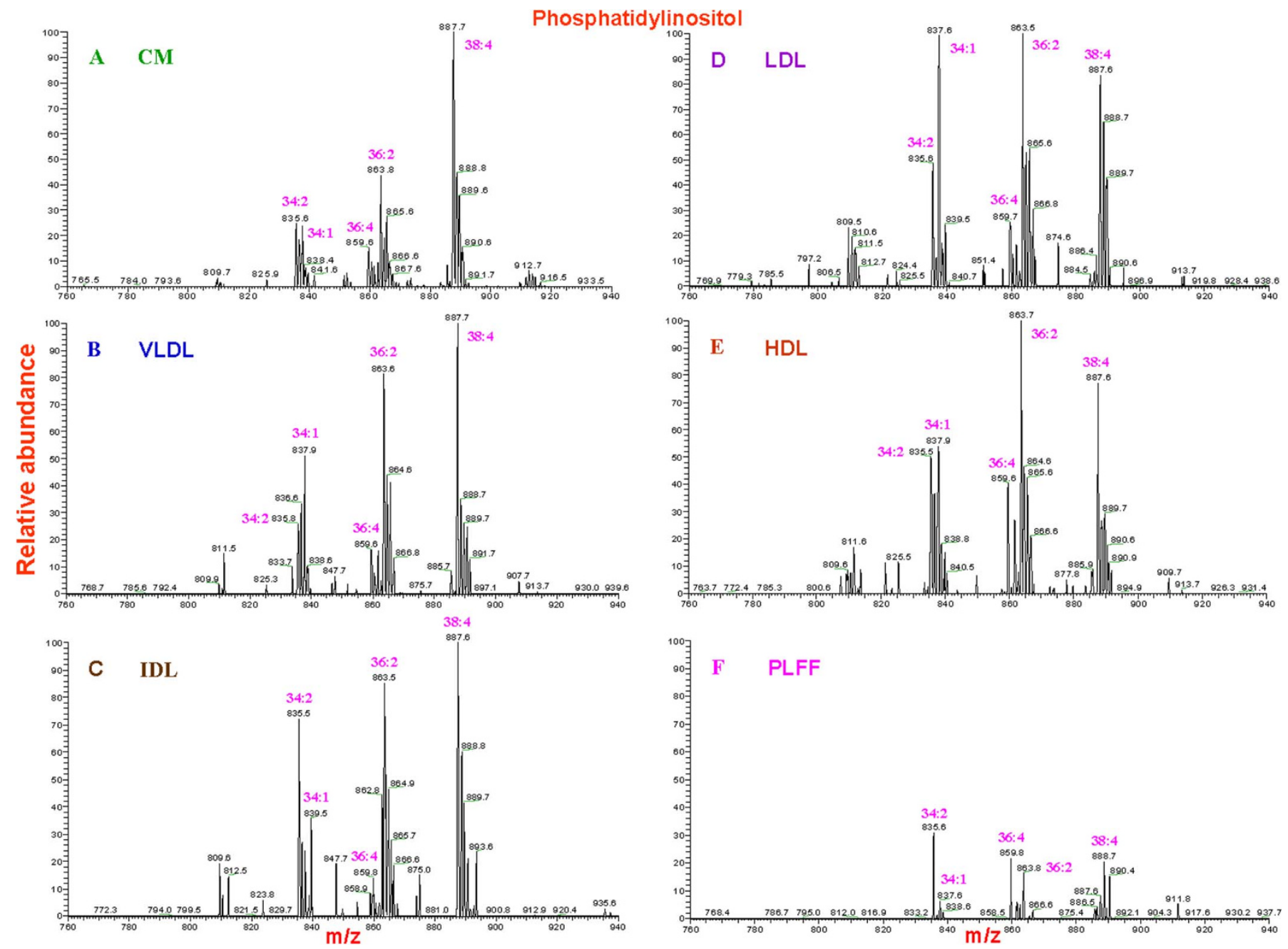

Figure 5 | High-performance liquid chromatography electrospray ionization tandem mass spectrometry analysis of plasma lipoproteins and plasma lipoprotein free fraction. We did not observe any adducts ions like $\mathrm{Na}$ or $\mathrm{K}$. positive scan $[\mathrm{M}+\mathrm{H}]+$. Characteristic part of the parent-scan for phosphatidylinositol (PI) in the corresponding retention time window. ' $36: 2$ ' specifies the composition of the protonated molecular ion as a species with $36 \mathrm{C}$-atoms in total in the acyl-chains with 2 unsaturated bonds in total; other assignments are analogous. (A) CM fraction, (B) VLDL fraction, (C) IDL fraction, (D) LDL fraction, (E) HDL fraction and (F) PLFF fraction.

clinical studies have stressed the atheroprotective and proatherogenic role of HDL and LDL respectively, ${ }^{37,38}$ further studies of these particles have become even more crucial. In this study, as first step, we applied a LC-ESI/MS and LC-ESI-MS/MS strategy to lipoprotein fractions to identify lipoprotein-associated phospholipids. Due to its high sensitivity, selectivity and specificity, LC-ESI-MS/MS is without parallel the most sophisticated technique for assessing the lipid composition of biological samples such as the phospholipid content of plasma lipoproteins. Lipoproteins were isolated from human pooled plasmas and the quality of purity of collected lipoproteins (VLDL, IDL, LDL and HDLs) was determined using three independent techniques: HPGC, nephelometry and Western blotting ${ }^{32}$. Furthermore, it is basically impossible to separate chylomicrones from VLDL to collect the pure VLDL or CM due to the continuum of VLDL and CM sizes by ultracentrifugation and HPGC. Although CM and VLDL fraction could be contaminated with each other, the first fraction was rich in CM and the second one rich in VLDL. However, we did not observe any specific differences between the fraction rich in CM and VLDL fraction with respect to phospholipid composition.

Nephelometric analysis exhibited that apo A-I (the major constituent of HDL) was only observed in the HDL fractions, whereas apo B (the major constituent of CM, VLDL, IDL and LDL) was not. Furthermore, cholesterol analysis, protein analysis and elution behaviour of ultracentrifugation isolated VLDL, IDL (extra purified steps by HPGC), LDL, HDL and PLFF confirmed the purity of the fractions. Finally, Western blot analysis revealed the absence of apo B in the isolated HDL fractions and the presence of apo B in the isolated CM, VLDL, IDL and LDL fractions. These results confirm the utility of our strategy to collect lipoprotein fractions from plasma that was not contaminated with other lipoproteins, although CM and VLDL fractions could be contaminated with each other.

LC-ESI/MS analysis resulted in the identification of sphingomyelin, PE, PI, PC and Lyso-PC in all lipoprotein fractions. However, we did not observe PG, PS and CL in plasma lipoprotein and lipoprotein free fractions. This could be due to the presence of only very low amounts of these phospholipids (below the detection limit of the LCESI-MS technique) in plasma lipoproteins and lipoprotein free fractions under normal conditions in plasma. The very low abundances of these phospholipids were also mentioned by Deguchi et a.l. ${ }^{39}$. Also, PG constitutes $2 \%$ of the total plasma phospholipids as shown by Schwars et $a l .{ }^{40}$ and was confirmed by Uran et al. ${ }^{41}$. Since plasma divided in 9 fractions in this study, the concentration of PG (2\%) will be also divided in these 9 fractions. That could be the reason why PG was not detected in our samples.

LC-ESI-MS/MS was used as a complementary technique to improve selectivity and consequently the signal/noise ratio of the 

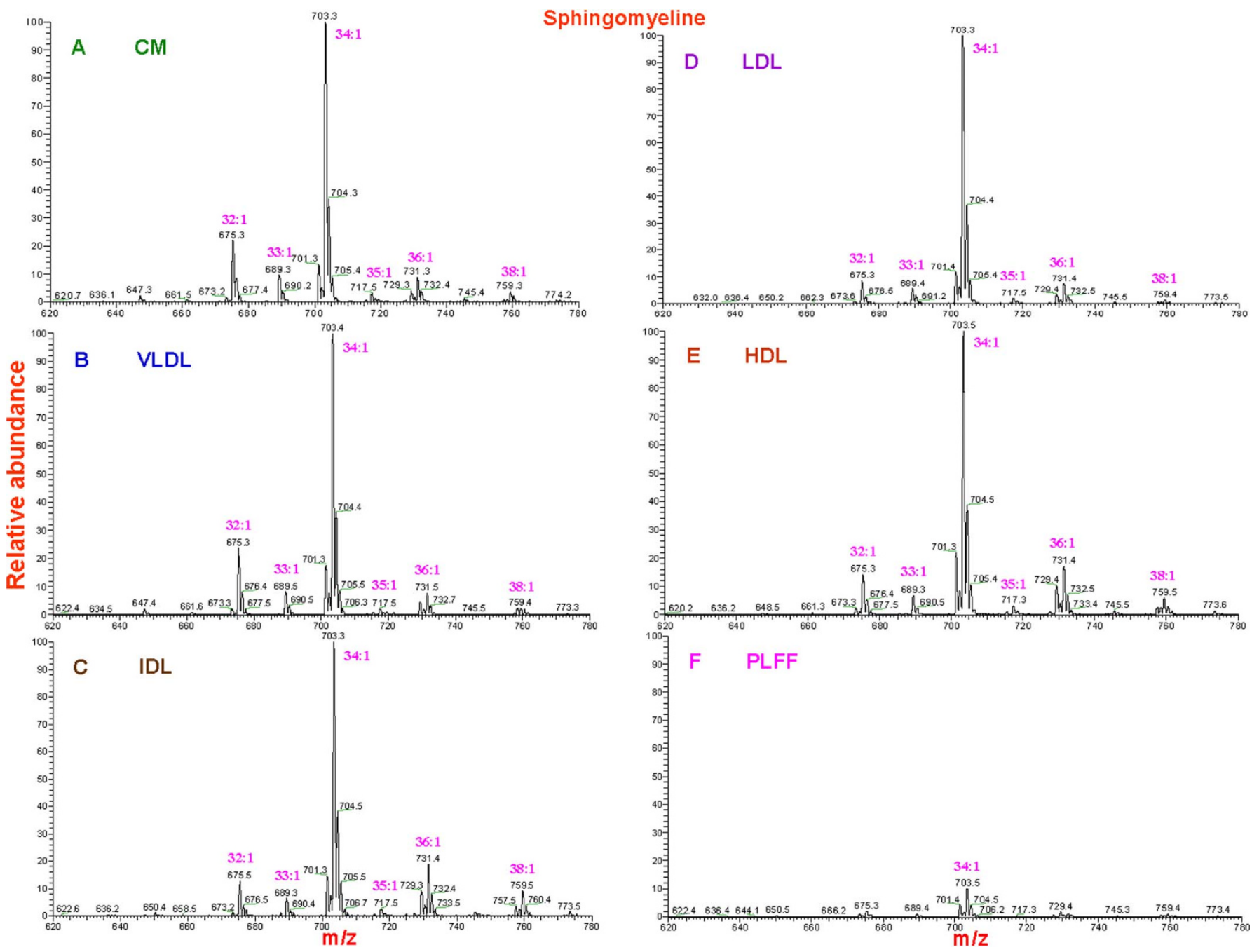

Figure 6 High-performance liquid chromatography electrospray ionization tandem mass spectrometry analysis of plasma lipoproteins and plasma lipoprotein free fraction. We did not observe any adducts ions like $\mathrm{Na}$ or K. positive scan $[\mathrm{M}+\mathrm{H}]+$. Characteristic part of the parent-scan for sphingomyeline (SM) in the corresponding retention time window. '34:1' specifies the composition of the protonated molecular ion as a species with 34 $\mathrm{C}$-atoms in total in the acylchain and alkyl chain of the sphingosine moiety with 1 unsaturated bond in total; other assignments are analogous. (A) CM fraction, (B) VLDL fraction, (C) IDL fraction, (D) LDL fraction, (E) HDL fraction and (F) PLFF fraction.

preselected compound classes; overall it lowers limit of detections (LOD). By using the MS/MS mode (classes of) compounds can easily be identified, filtering out the interference of all those compounds that do not meet the MS/MS conditions. LC-ESI-MS/MS approach led to the identification of the same phospholipids as we identified in the different fractions when we used LC-ESI-MS, Indicating that LCESI-MS/MS confirms the results obtained by LC-ESI-MS.

It is intriguing to note that PE, PI and SM were only observed in plasma lipoproteins and not in PLFF. This finding confirmed the specificity of our utility to identify lipoprotein-associated phospholipids. Furthermore, on searching the literature, we were unable to find any study in which the plasma lipoprotein free fractions were used as control for plasma lipoproteins. In addition, HPTLC was used as an alternative method to support and confirm the results obtained by MS and tandem MS approach regarding phospholipids composition of the major plasma lipoproteins. Three independent strategies led to the identification of a similar lipoprotein-associated phospholipids pattern, indicating a high confidence in the obtained results. Interestingly, the molecular profile appeared to be conserved between the different lipoproteins even though the concentrations of the lipid classes show slight differences except for PC species $38: 2$, 38:4 and 40:6 in CM fraction. These three PC species were only detected in $\mathrm{CM}$ fraction and were complete absent in other fractions.
Although LC-ESI-MS and LC-ESI-MS/MS were applied as qualitative approach, HPTLC was used as semi-quantitative in this study. MS and tandem MS were used as qualitative approach, because of three points: 1- the use of different internal standard for each plasma lipoprotein fraction, 2 ; the use of different internal standard for each main phopholipid and lipid species and 3; the combination of step 1 and 2 increase the complexity of samples and in turn the use of many different internal standards hampered to obtain correct quantification. This complexity was also described by Uran et al. ${ }^{41}$. However, Uran et al. $^{41}$ have shown a limit detection of 0.1-5 ng for bloodassociated phospholipids. For this reason, HPTLC was used as semi-quantitative approach in this study and not MS approach.

Numerous studies show that low HDL-C can be considered as an independent risk factor of atherosclerosis even when LDL-C is $10 w^{42}$. In addition, it is also well studied that increased HDL-C reduces the risk for cardiovascular disease $\mathrm{e}^{42,43}$. Although there are many available strategies to increase the HDL-C, the present available therapies with the current drugs have a limited effect because of low efficacy and severe side effects of these drugs ${ }^{29}$. An alternative therapy for the increase of the HDL-C levels is PI therapy via diet as shown recently by Burgess et al. and the others ${ }^{29-31}$. Burgess et al. have shown that PI stimulates cholesterol reverse transport via an increased efflux from peripheral tissues to HDL and in turn the transport of cholesterol 

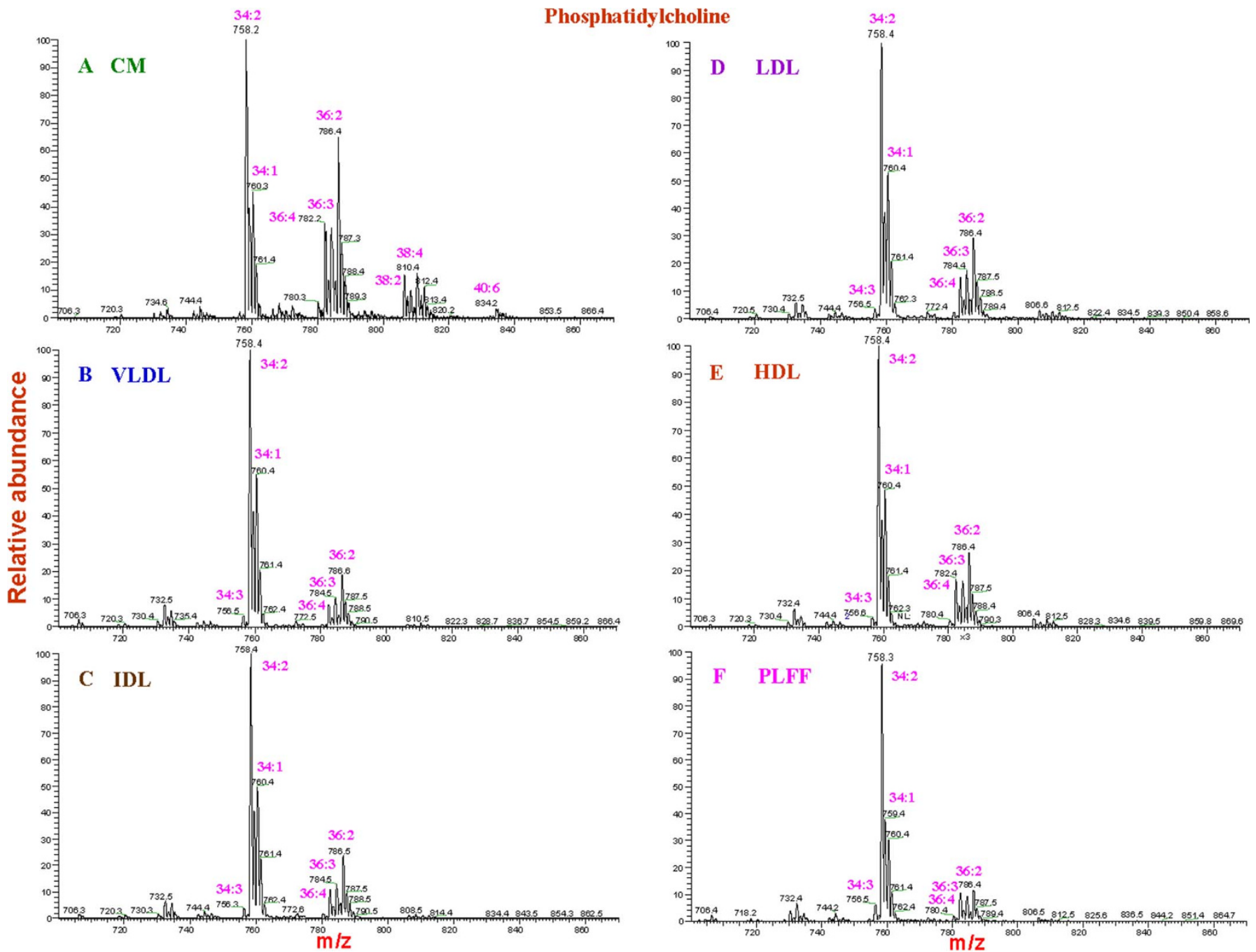

Figure 7 | High-performance liquid chromatography electrospray ionization tandem mass spectrometry analysis of plasma lipoproteins and plasma lipoprotein free fraction. We did not observe any adducts ions like $\mathrm{Na}$ or $\mathrm{K}$. positive scan $[\mathrm{M}+\mathrm{H}]+$. Characteristic part of the parent-scan for phosphatidylcholine (PC) in the corresponding retention time window. ' $34: 2$ ' specifies the composition of the protonated molecular ion as a species with $34 \mathrm{C}$-atoms in total in the acyl-chains with 2 unsaturated bonds in total; other assignments are analogous. (A) CM fraction, (B) VLDL fraction, (C) IDL fraction, (D) LDL fraction, (E) HDL fraction and (F) PLFF fraction.

from HDL to the liver, bile, and faeces for clearance or removing ${ }^{29-31}$. They have also demonstrated that when PI is taken orally during two weeks therapy leads on the one side the increase of apo-AI concentrations and on the other side the decrease of plasma triglyceride levels ${ }^{29-31}$. Our results revealed that PI is only present on plasma lipoproteins, and this may increases the specificity of therapy with PI via diet to affect the lipoprotein composition levels. Although the mechanism study of PI effect on lipoprotein is beyond our study, the PI therapy via diet is very simple and performable without major and severe side effects.

Another novel finding in this study is also the presence of SM only on lipoproteins. Although SM plays a major role in the constitution of all lipoproteins, the physiological function of SM in plasma is not until recently clear. Papasani et al. ${ }^{44}$ have shown that SM inhibits the oxidation of lipoproteins. Furthermore, Rey et $a l^{45}$ have shown in reconstituted high density lipoproteins studies that SM influences the structure of discoidal and spherical rHDL as well as it inhibits the LCAT reaction in discoidal $\mathrm{rHDL}$. It has been recently suggested that presence of SM in the lipoprotein surface involved in lipoprotein lipase-mediated lipolysis, and that cholesterol enrichment in the lipoprotein surface does not affect lipolysis ${ }^{46,47}$. Moreover, it has been reported that SM can be used as marker for the clearance of remnant-like particles ${ }^{48}$. Also, Jiang et al. have suggested that plasma SM concentration is a risk factor for atherosclerotic process ${ }^{49}$. Although the function of SM in lipoproteins remains to be fully clarified, the SM could be also considered as an alternative therapy and pharmacological intervention to affect lipoprotein levels. To our knowledge, the observed effects of $\mathrm{PI}^{29-31}$ and $\mathrm{SM}^{43-48}$ in plasma could be only possible via lipoproteins, since PI and SM were only present on lipoproteins (with high intensity of SM in LDL fraction) and not detected in plasma lipoprotein free fractions.

Next to other studies, ${ }^{19,27,50}$ our approach also revealed the presence of PE on lipoproteins. Recently, Agren et al. ${ }^{51}$ demonstrated that there is a selective secretion of PE and sphingomyelin molecular species during VLDL secretion when they compare the molecular species phospholipids content of VLDL with liver phospholipids composition. Furthermore, it has been recently shown that Prothrombinase enhancement through quantitative and qualitative changes appear to affect very low density lipoprotein in complex with C-reactive protein, and the qualitative changes appeared to be resulted from a deficiency of PE in VLDL from disseminated intravascular coagulation patients with the biphasic waveform ${ }^{52}$. In addition, Phosphatidylethanolamine N-methyltransferase appears to be an essential component in the secretion of apoB100-containing 

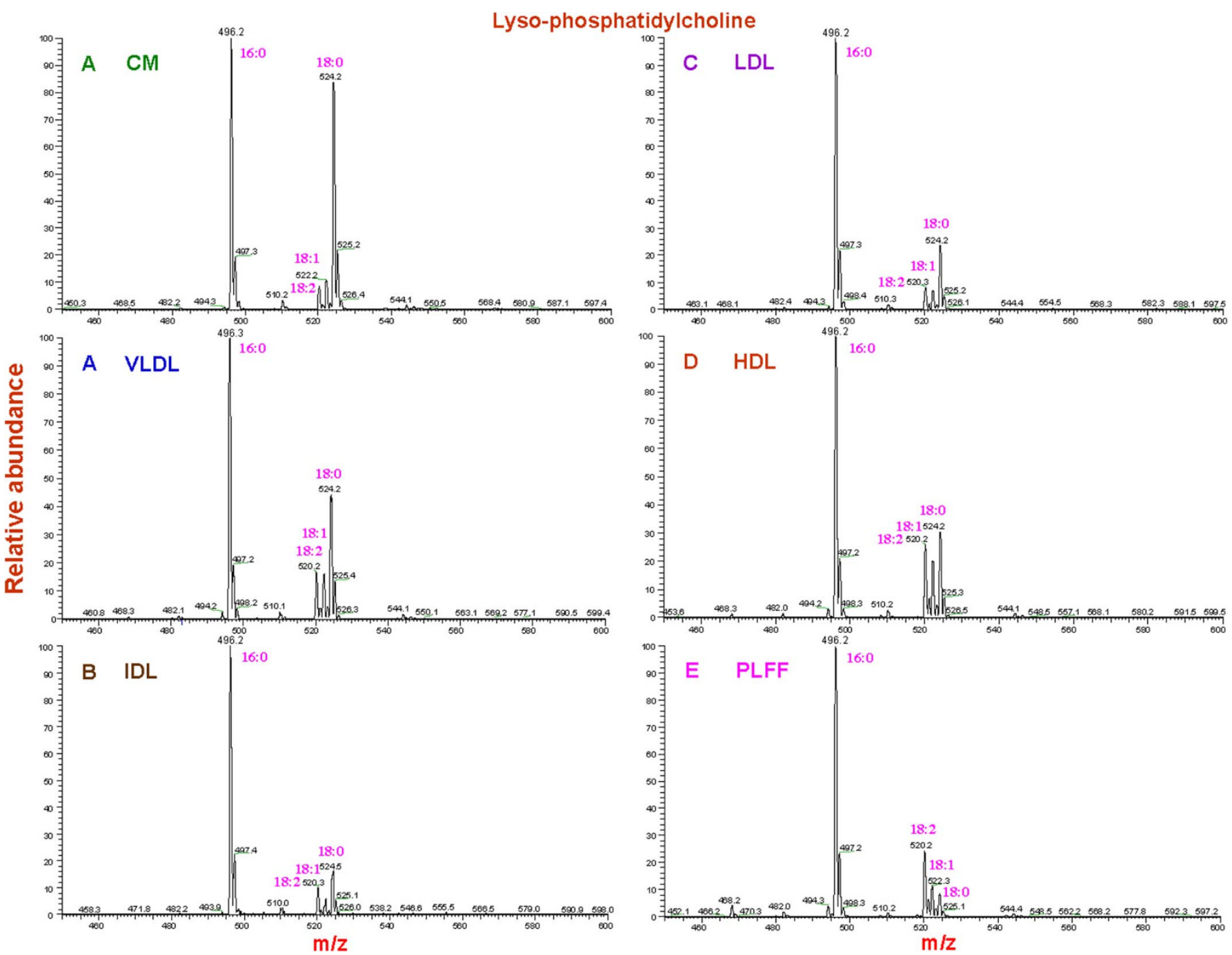

Figure 8 High-performance liquid chromatography electrospray ionization tandem mass spectrometry analysis of plasma lipoproteins and plasma lipoprotein free fraction. We did not observe any adducts ions like $\mathrm{Na}$ or $\mathrm{K}$. positive scan $[\mathrm{M}+\mathrm{H}]+$. Characteristic part of the parent-scan for lysophosphatidylcholine (LPC) in the corresponding retention time window. ' $18: 0$ ' specifies the composition of the protonated molecular ion as a species with $18 \mathrm{C}$-atoms in the acyl-chain with 0 unsaturated bonds in total; other assignments are analogous. (A) CM fraction, (B) VLDL fraction, (C) IDL fraction, (D) LDL fraction, (E) HDL fraction and (F) PLFF fraction.

VLDLs ${ }^{53}$. Since PE is only present in lipoproteins, (with highest abundancy in VLDL fraction) its physiological role could be only possible via lipoproteins.

LC-ESI/MS analysis further revealed the presence of PC and LysoPC on lipoproteins. Parthasarathy et al. have reported that $40 \%$ of the $\mathrm{PC}$ in LDL is converted to lyso-PC during oxidized modification. Also, the lyso-PC concentration is shown to be increased in atherosclerotic plaques in mice fed an atherogenic diet ${ }^{54,55}$. Furthermore, Lyso-PC induces human coronary artery Smooth muscle cells migration $^{56}$. In addition, Lyso-PC increased in atherogenic lipoproteins and atherosclerotic lesions, and has been shown to stimulate transcription of a variety of endothelial genes relevant to atherogenesis ${ }^{57}$.

In summary, this study resulted in the identification of 5 phospholipids associated with lipoproteins of which PE, PI and SM were only present in lipoproteins. The role of these identified lipoprotein-associated phospholipids in atherothrombosis awaits further investigation and may provide new insights into the mechanism(s) of atherothrombotic diseases and the future pharmacological intervention.

\section{Methods}

Materials. Human blood was drawn from overnight-fasted normal healthy volunteers after informed consent, by venipuncture into tubes containing sodium-citrate as anticoagulant. Subsequently, plasma was obtained by centrifugation at $1,000 \mathrm{x} g$ for 15 minutes at $4{ }^{\circ} \mathrm{C}$ and used freshly or stored at $-80^{\circ} \mathrm{C}$ for further analysis. All experiments were performed in accordance with relevant guidelines and regulations and had the approval of the local Medical ethical committee (Academic Medical Center Amsterdam/ Univerisity Medical Center Groningen).

Lipoprotein isolation by salt-gradient ultracentrifugation. One-step ultracentrifugation was used according to Kleinfeld et al..$^{33}$ with some modifications (omission of sucrose in the salt gradient, and use of a 103,000 $\mathrm{xg}$ instead of a $200,000 \mathrm{x}$ g centrifugation step) to obtain the major lipoprotein fractions (VLDL, IDL, LDL, and HDL) and HDL-2 and VHDL as well as Plasma Lipoprotein Free Fraction (PLFF). In this study, all plasma lipoprotein fractions were analyzed except Lipoprotein small a (LPa) and that was due to very small amount of extracted lipid fraction. The collected lipoprotein fractions were concentrated by concentrator (Eppendorf) and were freshly used in the experiments and the rest stored for 10 days at $4^{\circ} \mathrm{C}$. Only for the isolation of chylomicrons $(\mathrm{CM})$ we applied other approach.

CM isolation. $12 \mathrm{ml}$ non-fasted plasma was spun in a SW41.14 rotor for 1 hour at $29000 \mathrm{rpm}$ in a Beckman ultracentrifuge. The top $3 \mathrm{ml}$ was collected and spun under the same conditions. The top approximately $2.5 \mathrm{ml}$ was again eluted and spun under the same circumstances. Finally, the top $2 \mathrm{ml}$ collected fraction (rich in CM) was subjected to one-step ultracentrifugation according to Kleinfeld et al. ${ }^{33}$ with some modifications. This strategy was taken to remove as much VLDL possible from the chylomicrons fraction. All ultra, HPGC and mass spectrometry experiments involved $\mathrm{CM}$ fraction were separately performed en analyzed. 


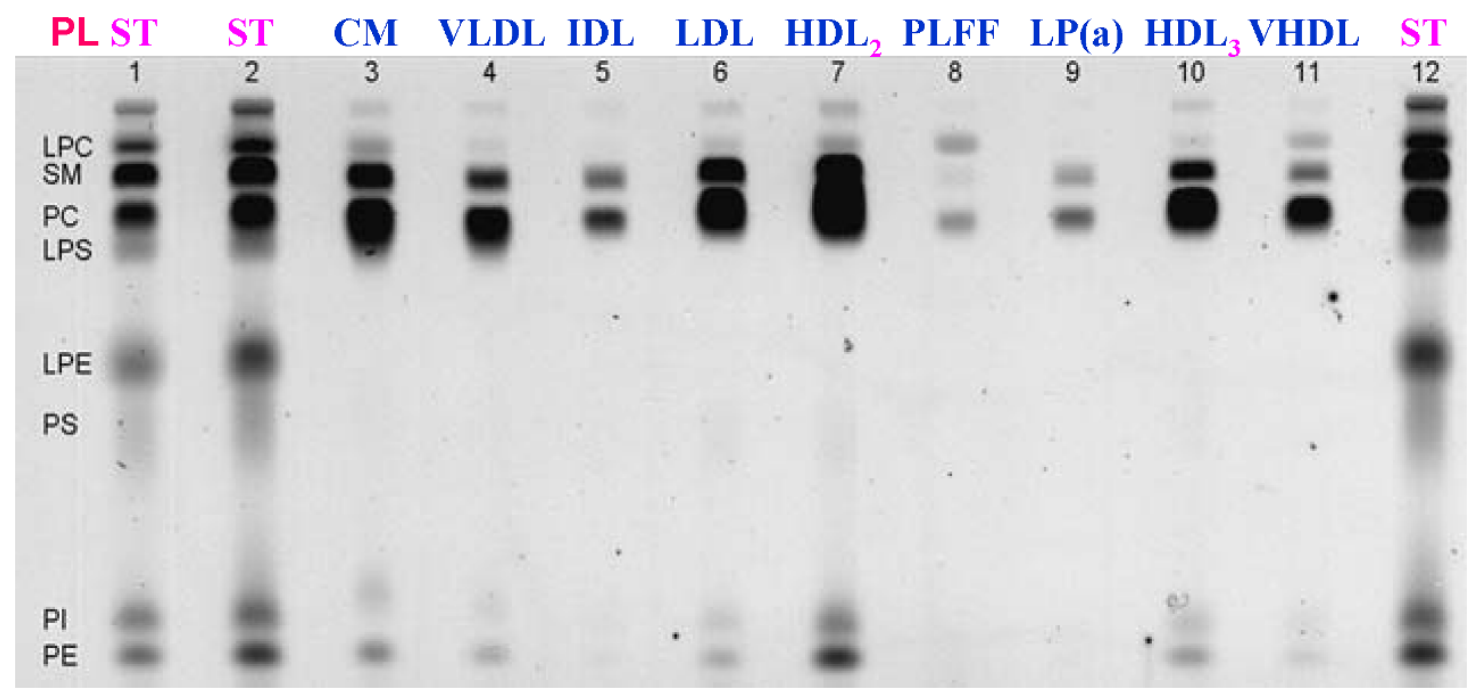

Figure 9 | Separation of phospholipids from plasma lipoprotein fractions and plasma lipoprotein free fraction by HPTLC. Plasma lipoprotein phospholipid composition and PLFF fraction were extracted and applied to one-dimensional, horizontal HPTLC as described under Materials and Methods. Representative separations are shown of a mixture of purified (ST=standard) phospholipids (lane $1(10 \mu \mathrm{l}), 2$ and $12(20 \mu)$ ). The following concentration of phospholipids (PL) were used in standard mixture and expressed in ng/ $\mu$ l (Lyso-PC 51, SM 101.8, PC 100, PI 50, PE 49.7, Lyso-PS 67.2, Lyso-PE 53 and PS 50.2). The following volumes of lipoprotein phospholipids extracts were utilized in HPTLC (Chylomicrons (lane 3, $3 \mu \mathrm{l}$ ), VLDL (lane 4, $4 \mu \mathrm{l}$ ), IDL (lane 5, $5 \mu \mathrm{l}$ ), LDL (lane 6, $2 \mu \mathrm{l}$ ), $\mathrm{HDL}_{2}$ (lane 7, $2 \mu \mathrm{l}$ ), PLFF (lane 8, $5 \mu \mathrm{l}$ ), $\operatorname{Lp}(\mathrm{a})($ lane 9, $2 \mu \mathrm{l}), \mathrm{HDL}_{3}($ lane 10, $4 \mu \mathrm{l})$, and VHDL (lane 11, $5 \mu \mathrm{l})$. The different phospholipids composition of standard mixture is indicated on the left and lane number on the top of figure.

Table 2 | Global relative abundance of each phospholipid based on the intensity of the most intense peak. PHOSPHOLIPIDS

\begin{tabular}{|c|c|c|c|c|c|c|c|c|}
\hline PLF & $P E$ & PG & PS & $\mathrm{PI}$ & PC & $S M$ & LP-C & $\mathrm{CL}$ \\
\hline
\end{tabular}

Relative abundance of phospholipids in the different plasma lipoprotein fractions were indicated by + , Very small traces of a detected phospholipids are indicated by small + . The abbreviations are: Plasma lipoprotein fraction (PLPF), Plasma lipoprotein free fraction (PLFF) and not detected (nd). The results for CM fraction was obtained in a separate tandem MS run, hence relative intensity of CM were not included in this table. A similar pattern was observed for the phospholipids composition of CM and other lipoprotein fractions, although CM fraction was separately analyzed. Please see the list of abbreviation in supplement.

High performance gel-permeation chromatography (HPGC), cholesterol analysis and protein analysis. The cholesterol profiles of the major lipoprotein types were determined applying HPGC $^{32-36} .60 \mu$ of lipoprotein fractions collected by ultracentrifugation was introduced to gel-permeation chromatography using a Superose 6 HR 10/30 column (Pharmacia Biotech, Uppsala, Sweden) ${ }^{32-35}$. Chromatographic profiles of commercially available plasma lipid standards (SKZL, Nijmegen, The Netherlands) served as a reference. To obtain a purified ultra IDL fraction, Ultra IDL fraction was repeatedly exposed to HPGC. The protein analysis was used for the ultra collected IDL fraction. All conditions for the protein analysis of the ultra collected IDL fraction are the same as above-mentioned procedure meant for the cholesterol analysis.

Nephelometry. Apo A-I and apo B content in the lipoprotein fractions were measured by immunoprecipitation using nephelometry in a BN ProSpec nephelometer protein analyser (Dade Behring, Marburg, Germany) according to the manufacturer's instruction. The reagents for the quantitative determination of apo A-I and apo B were purchased by Dade Behring (Dade Behring, Marburg, Germany).

Western blot analysis. 50-100 $\mu \mathrm{g}$ of protein present in the lipoprotein and plasma lipoprotein free fractions were denatured and separated by $7.5 \%(\mathrm{w} / \mathrm{v})$ SDS-PAGE and transferred from the gel to low fluorescent polyvinylidene difluoride (LPFPVDF) membranes (GE Healthcare Biosciences). The blots were then blocked at $4{ }^{\circ} \mathrm{C}$ for overnight. After blocking, blots were incubated with a monoclonal antibody against apo B (178444, Calbiochem, Darmstadt, Germany). Apolipoprotein B protein was purchased by sigma (Gmbh, Germany). Bound antibodies were detected with a CyDye-coupled goat anti-mouse antibody according to the manufacturer's instructions for ECL Plex Western Blotting System (GE Healthcare Biosciences). PageRuler prestained protein ladder (Fermentas, Germany) were run in parallel. The protein concentration of the lipoprotein fractions was determined by absorbance at $280 \mathrm{~nm}$ (an OD of 1 equals $1 \mathrm{mg} / \mathrm{mL}$ ).

Lipoprotein and plasma lipoprotein free fraction associated Phospholipid extraction. The phospholipids from $200 \mu \mathrm{l}$ of each plasma lipoprotein and lipoprotein free fractions (three independent Lipoprotein isolation by salt-gradient ultracentrifugation) were extracted with $4 \mathrm{ml}$ of ice-cold solution of chloroform: methanol $(1: 1 \mathrm{v} / \mathrm{v})$. The suspension was incubated for $30 \mathrm{~min}$ at $4{ }^{\circ} \mathrm{C}$. Subsequently, the mixture was centrifuged at $4,000 \mathrm{rpm}$ for $15 \mathrm{~min}$ at $4{ }^{\circ} \mathrm{C}$. The supernatant was collected and the pellets were treated with $3 \mathrm{ml}$ chloroform: methanol $(2: 1 \mathrm{v} / \mathrm{v})$ followed by incubation and centrifugation. The collected supernatants were pooled, pelletted under nitrogen gas, solubilized in chloroform: methanol: water $(50: 45: 5 \mathrm{v} / \mathrm{v})$ and stored at $-80^{\circ} \mathrm{C}$. This phospholipid extraction approach is a singlephase extraction (monophasic) $)^{58}$. Based on this monophasic approach, we assume that we did not loose any phospholipids in our plasma lipoprotein fractions.

Liquid Chromatography- ElectroSpray Ionization-MS (LC-ESI-MS). LC. The LC system consisted of an HP1100 series binary gradient pump, a vacuum degasser, a column temperature controller (all from Hewlett Packard, Wilmington, DE, USA) and a Gilson $231 \mathrm{XL}$ autosampler (Gilson, Villiers-le-Bel, France). $20 \mu \mathrm{L}$ of sample was loaded onto an analytical LiChrosphere Si 60 column $(250 \times 2 \mathrm{~mm}, 5 \mu \mathrm{m}$ particle size, Merck, Darmstadt, Germany) and the column temperature was maintained at $22{ }^{\circ} \mathrm{C}$. Samples were eluted with a flow rate of $0.3 \mathrm{~mL} / \mathrm{min}$ and a linear gradient between solution $\mathrm{A}\left(\mathrm{CH}_{3} \mathrm{OH} / \mathrm{H}_{2} \mathrm{O}, 90: 10 \mathrm{v} / \mathrm{v}, 0.1 \% \mathrm{NH}_{4} \mathrm{OH}\right)$ and solution $\mathrm{B}$ 
$\left(\mathrm{CHCl}_{3} / \mathrm{CH}_{3} \mathrm{OH}, 98: 2 \mathrm{v} / \mathrm{v}, 0.01 \% \mathrm{NH}_{4} \mathrm{OH}\right)$. The gradient was programmed: from $\mathrm{T}=0 \mathrm{~min}, 20 \% \mathrm{~A}$ and $80 \% \mathrm{~B}$ towards $\mathrm{t}=5 \mathrm{~min}, 100 \% \mathrm{~A} ; \mathrm{t}=5-8 \min 100 \% \mathrm{~A}$; $\mathrm{t}=8-8.1$ min change to $100 \% \mathrm{~B} ; \mathrm{t}=8.1-14 \mathrm{~min} 100 \% \mathrm{~B} . \mathrm{t}=14-14.1 \mathrm{~min}$ : return back to the starting composition; a flow of $0.5 \mathrm{ml} / \mathrm{min}$ was used to equilibrate the column. All gradient steps were linear, and the total analysis time, including the equilibration, was $18 \mathrm{~min}$.

A splitter between the LC column and MS allowed introduction of eluant with a flow of $30 \mu \mathrm{l} / \mathrm{min}$. An electrically operated valve selected the introduction of eluant in the MS between $\mathrm{t}=3$ and $14 \mathrm{~min}$.

ElectroSpray Ionization-Mass Spectrometry (ESI-MS). A Quattro II triple-quadrupole mass spectrometer (Micromass, Manchester, UK), was used in the positive and negative electrospray ionization (ESI) mode. Nitrogen was used as nebulizing gas and argon was used as collision gas at a pressure of $2.5 \times 10^{-3} \mathrm{mBar}$ (collision energy $20-40 \mathrm{eV}$ ). The capillary voltage used was $3 \mathrm{KV}$. The source temperature was set at $80^{\circ} \mathrm{C}$ and optimal cone voltage was $45 \mathrm{~V}$. Full scans were acquired between $(+/-) \mathrm{m} / \mathrm{z}$ 400 and $(+/-) \mathrm{m} / \mathrm{z} 1000$ in $3 \mathrm{~s} / \mathrm{scan}$. Specific phospholipid identities were confirmed by the characteristic constant neutral loss or parent scans in the corresponding retention time windows (for PE). All LC-ESI/MS experiments were performed with two independent lipoprotein isolation by salt-gradient ultracentrifugation.

Liquid Chromatography -ESI-tandem Mass Spectrometry (LC-ESI-MS/ MS). LC. Chromatographic separation was achieved on a Surveyor modular LC System (Thermo Finnigan Corporation, San Jose, CA, USA) consisting of a thermostated autosampler, a low-flow quaternary MS pump and a $2.1 \times 250 \mathrm{~mm}$ silica column, $5 \mu \mathrm{m}$ (particle size) (Merck, Darmstadt, Germany).

Samples were eluted with a flow rate of $0.3 \mathrm{ml} / \mathrm{min}$ and a linear gradient between solution $\mathrm{A}\left(\mathrm{CH}_{3} \mathrm{OH} / \mathrm{H}_{2} \mathrm{O}, 85: 15 \mathrm{v} / \mathrm{v}, 0.1 \% \mathrm{NH}_{4} \mathrm{OH}\right)$ and solution $\mathrm{B}\left(\mathrm{CHCl}_{3} / \mathrm{CH}_{3} \mathrm{OH}\right.$, $97: 3 \mathrm{v} / \mathrm{v}, 0.01 \% \mathrm{NH}_{4} \mathrm{OH}$ ). The gradient was programmed: from $\mathrm{T}=0 \mathrm{~min}, 20 \% \mathrm{~A}$ and $80 \% \mathrm{~B}$ towards $\mathrm{T}=10 \mathrm{~min}, 100 \% \mathrm{~A} ; \mathrm{T}=10-12 \mathrm{~min} 100 \% \mathrm{~A} ; \mathrm{T}=12-12.1$ min change to $100 \% \mathrm{~B} ; \mathrm{T}=12.1-17 \mathrm{~min} 100 \% \mathrm{~B} . \mathrm{T}=17-17.1 \mathrm{~min}$ : return back to the starting composition. A splitter between the LC column and the mass spectrometer was used; $75 \mu \mathrm{l} / \mathrm{min}$ was introduced into the mass spectrometer.

ESI-MS/MS analysis. MS/MS analyses were performed on a TSQ Quantum AM (Thermo Finnigan Corporation, San Jose, CA, USA) operated alternating in the negative- and positive ion electrospray ionization (ESI) mode in consecutive runs. The SID was set at $10 \mathrm{~V}$; spray voltage was $3600 \mathrm{~V}$ and the capillary temperature was $300{ }^{\circ} \mathrm{C}$. In the MS/MS experiments Ar was used as collision gas at a pressure of 0.5 mtorr; collision energy ranged between $20-40 \mathrm{eV}$ for the different optimized transitions. In the negative mode mass spectra were obtained by continuous scanning between $\mathrm{m} / \mathrm{z} 400-\mathrm{m} / \mathrm{z} 1000(2 \mathrm{~s} / \mathrm{scan})$. In the positive mode characteristic constant neutral loss (CNL) or parent $(\mathrm{P})$ scans were used to selectively detect specific phospholipids in their corresponding retention time windows: CNL (141) for PE, CNL (172) for PG, (260) for PI, CNL (185) for PS, CNL and P (184) for PC, LPC, SM ${ }^{59}$ CNL (172) for PG and (260) for PI was described previously by Sommer et al. ${ }^{60}$, and Cole et al. ${ }^{61}$

Cardiolipins are easily identified based upon their retention time and typical clusters of doubly charged ions as described previously by Houtkooper et al..$^{58}$ and Han et al. ${ }^{62}$ and we applied this approach to determine CL in plasma lipoprotein samples.

High Performance Thin Layer Chromatography (HPTLC). HPTLC was performed as described previously. ${ }^{36}$ Very short description: TLC was applied on HPTLC plates, which is purchased from Merck (Darmstadt, Germany). The impurities of plates were removed by methanol: ethyl acetate treatment $(6: 4)$ in a Camag horizontal developing chamber. The plates were activated for $10 \mathrm{~min}$ at $130^{\circ} \mathrm{C}$. Samples and one mixture of phospholipids standards were applied to one HPTLC-plate. Subsequently, the plate was developed in a Camag horizontal developing chamber.

The HPTLC-plate was dried under an air stream $\left(40^{\circ} \mathrm{C}\right)$ on a heating plate (DESAGA, Heidelberg, Germany) for $10 \mathrm{~min}$ at $40^{\circ} \mathrm{C}$. Finally, phospholipids were separated as described previously. ${ }^{36}$

1. Ross R. The pathogenesis of atherosclerosis: a perspective for the 1990s. Nature. 362, 801-809 (1993)

2. Berliner, J. A., et al. Atherosclerosis: basic mechanisms. Oxidation, inflammation, and genetics. Circulation 91, 2488-2496 (1995).

3. Castelli, W. P., Garrison, R. J., Wilson, P. W. Abbott, R. D., Kalousdian, S. \& Kannel, W. B. Incidence of coronary heart disease and lipoprotein cholesterol levels. The Framingham Study. JAMA 256, 2835-2838 (1986).

4. Atkinson, D. \& Small, D. M. Recombinant lipoproteins: implications for structure and assembly of native lipoproteins. Annu Rev Biophys Biochem 15, 403-456 (1986).

5. Mahley, R. W. Innerarity TL, Rall SC, Weisgraber KH. Plasma lipoproteins: apolipoprotein structure and function. J. Lipid Res 25, 1277-1288 (1984).

6. Davidson, W. S., Sparks, D. L., Lund-Katz, S. \& Phillips MC. The molecular basis for the difference in charge between pre-beta- and alpha-migrating high density lipoproteins. J Biol Chem 269, 8959-65 (1994).

7. Cushley, R. J. \& Okon, M. NMR studies of lipoprotein structure. Annu. Rev Biophys Biomol Struct 31, 177-206 (2002).
8. Tollefson, J. H., Ravnik, S. \& Albers, J. J. Isolation and characterization of a phospholipid transfer protein (LTP- II) from human plasma. J Lipid Res $\mathbf{2 9}$, 15931602 (1988).

9. Tall, A. R., Krumholz, S., Olivecrona, T. \& Deckelbaum, R. J. Plasma phospholipid transfer protein enhances transfer and exchange of phospholipids between very low density lipoproteins and high density lipoproteins during lipolysis. J Lipid Res 26, 842-851 (1985).

10. Tu, A. Y., Nishida, H. I. \& Nishida T. High density lipoprotein conversion mediated by human plasma phospholipid transfer protein. J Biol Chem 268, 23098-231059 (1993)

11. Wolfbauer, G., Albers, J. J. \& Oram, J. F. Phospholipid transfer protein enhances removal of cellular cholesterol and phospholipids by high density lipoprotein apolipoproteins. Biochim Biophys Acta 143, 965-76 (1999).

12. Bagdade, J. D., Buchanan, W. F., Pollare, T. \& Lithell H. Abnormal lipoprotein phospholipid composition in patients with essential hypertension. Atherosclerosis 117, 209-215 (1995).

13. Yancey, P. G., et al. In vivo modulation of HDL phospholipid has opposing effects on SR-BI- and ABCA1-mediated cholesterol efflux. J Lipid Res 45, 337-346 (2004).

14. Yancey, P. G., et al. High density lipoprotein phospholipid composition is a major determinant of the bi-directional flux and net movement of cellular free cholesterol mediated by scavenger receptor BI. J Biol Chem 275, 36596-36604 (2000).

15. Baker, P. W., Rye, K. A., Gamble, J. R., Vadas, M. A. \& Barter, P. J. B. vascular cell adhesion molecule-1 in human umbilical vein endothelial cells. J. Lipid. Res $\mathbf{4 0}$, 345-353 (1999).

16. Baker, P. W., Rye, K., Gamble, J. R., Vadas, M. A. \& Barter, P. B. Phospholipid composition of reconstituted high density lipoproteins influences their ability to inhibit endothelial cell adhesion molecule expression. J Lipid Res 41, 1261-1267 (2000).

17. Subbaiah, P. V. \& Pritchard, P. H. Molecular species of phosphatidylcholine in familial lecithin-cholesterol acyltransferase deficiency: effect of enzyme supplementation. Biochim Biophys Acta 1003, 145-150 (1989).

18. Ashby, D., et al. Lack of effect of serum amyloid A (SAA) on the ability of highdensity lipoproteins to inhibit endothelial cell adhesion molecule expression. Atherosclerosis 154, 113-121 (2001)

19. Fournier, N., et al. HDL Phospholipid Content and Composition as a Major Factor Determining Cholesterol Efflux Capacity From Fu5AH Cells to Human Serum. Arterioscler. Thrombo Vasc Biol 17, 2685-2691 (1997).

20. Xia, P., Vadas, M. A, Xia, P., Vadas, M. A, Rye, K. A., Barter, P. J. \& Gamble JR. High Density Lipoproteins (HDL) Interrupt the Sphingosine Kinase Signaling Pathway: A possible mechanism for protection against atherosclerosis by HDL. $J$ Biol Chem 274, 33143-33147 (1999).

21. Piperi, C., Kalofoutis, C., Tzivras, M., Troupis, T., Skenderis, A. \& Kalofoutis, A. Effects of hemodialysis on serum lipids and phospholipids of end-stage renal failure patients. Mol. Cell Biochem 265, 57-61 (2004).

22. Pruzanskia, W., Stefanski, E., de Beer, F. C., de Beer, M. C., Ravandi, A. \& Kuksis, A. Comparative analysis of lipid composition of normal and acute-phase high density lipoproteins. J Lipid Res 41, 1035-047 (2000).

23. Van Lenten, B. J., et al. Anti-inflammatory HDL becomes pro-inflammatory during the acute phase response. Loss of protective effect of HDL against LDL oxidation in aortic wall cell co cultures. J Clin Invest 96, 2758-2767 (1995).

24. Ibdah, J. A, Lund-Katz, S. \& Philips, M. C. Molecular packing of high-density and low-density lipoprotein surface lipids and apolipoprotein A-I binding. Biochemistry 28, 1126-33 (1989).

25. Verkade, H. J., Fast, D. G., Rusinol, A. E., Scraba, D. G. \& Vance, D. E. Impaired biosynthesis of phosphatidylcholine causes a decrease in the number of very low density lipoprotein particles in the Golgi but not in the endoplasmic reticulum of rat liver J Biol Chem 268, 24990-24996 (1993).

26. Fast, D. G., Fast, D. G., Vance, D. E. Nascent, M. VLDL phospholipid composition is altered when phosphatidylcholine biosynthesis is inhibited: evidence for a novel mechanism that regulates VLDL secretion. Biochim Biophys Acta 1258, 159-168 (1995).

27. Klein, S., Spannagl, M. \& Engelmann, B. Phosphatidylethanolamine Participates in the Stimulation of the Contact System of Coagulation by Very-Low-Density Lipoproteins. Arterioscler Thrombo Vasc Biol 21, 1695-1700 (2001).

28. Navab M, Hama S, Hough G, Fogelman AM. Oral synthetic phospholipids (DMPC) raise high-density lipoprotein cholesterol levels, improve high-density lipoprotein function, and markedly reduce atherosclerosis in apolipoprotein Enull mice. Circulation 108, 1735-1739 (2003).

29. Burgess, J. W., Neville, T. A. M., Rouillard, P., Harder, Z., Beanlands, D. S. \& Sparks DL. Phosphatidylinositol increases HDL-C levels in humans. J Lipid Res 46, 350-355 (2005).

30. Stamler, C. J., Breznan, D., Neville, T. A., Viau, F. J., Stamler, C. J., Breznan, D. Neville, T. A., Viau, F. J., Camlioglu, E. \& Sparks DL. Phosphatidylinositol promotes cholesterol transport in vivo. J Lipid Res 41, 1214-1221 (2000).

31. Burgess, J. W., et al. Phosphatidylinositol promotes cholesterol transport and excretion. J Lipid Res 44, 1355-1363 (2000).

32. Rezaee, F., Casetta, B., Levels, J. H. M., Speijer, D. \& Meijers, J. C. M. Proteomic analysis of high-density lipoprotein. Proteomics 2, 721-730 (2006).

33. Queiroz, K. C., et al. Human Plasma Very Low Density Lipoprotein Carries Indian Hedgehog. J Proteome RES 9, 5052-5059 (2010). 
34. Kleinveld, H. A., Duif, P. F. \& Kleinveld, H. A., Duif, P. F. \& Pekelharing, H. L. Oxidation of lipoprotein(a) and low density lipoprotein containing density gradient ultracentrifugation fractions. Biochim Biophys Acta 1303, 15-21 (1996).

35. Levels, J. H. M., Abraham, P. R., van den Ende, A., van Deventer, S. J. H. Distribution and Kinetics of Lipoprotein-Bound End. Infect Immune 68, 28212828 (2001).

36. Weerheim, A. M., Kolb, A. M., Sturk, A. \& Nieuwland, R. Phospholipid Composition of Cell-Derived Microparticles Determined by One-Dimensional High-Performance Thin-Layer Chromatography. Analy Biochem 302, 191-198 (2002).

37. Sachinidis, A., et al. Evidence that lipoproteins are carriers of bioactive factors. Arterioscler.Thromb Vasc Biol 19, 2412-2421 (1999).

38. Nofer, J. R., et al. Suppression of Endothelial Cell Apoptosis by High Density Lipoproteins (HDL) and HDL-associated Lysosphingolipids. J Biol Chem 276, 34480-34485 (2001).

39. Deguchi, H., Fernandez, J. A., Hackeng, T. M., Banka, C. L. \& Griffin, J. H. Cardiolipin is a normal component of human plasma lipoproteins. Proc Natl Acad Sci U S A 97, 1743-1748 (2000).

40. Schwarz, H. P., Dahike, M. B. and Dreisbach, L. Phospholipid composition of blood plasma, Erythrocytes and "Ghosts" in Sickle Cell Disease. CLIN CHEM 23 1548-1550 (1977).

41. Uran, S., smund, A., Petter, L., Jacobsen, B. and Skotland, T. Analysis of phospholipid species in human blood using normal-phase liquid chromatography coupled with electrospray ionization ion-trap tandem mass spectrometry. J of Chromato B 758, 265-275 (2001).

42. Castelli, W. P. Cholesterol and lipids in the risk of coronary artery disease. The Framingham Heart Study. Can J Cardiol 4 Suppl A 5A-10A (1988).

43. Gordon, T., Castelli, W. P., Hjortland, M. C., Kannel, W. B. \& Dawber, T. R. High density lipoprotein as a protective factor against coronary heart disease. The Framingham Study. Am J Med 62, 707-714 (1997).

44. Papasani, V. S., Veedamali, S. S. \& Kewei, W. Novel Physiological Function of Sphingomyelin in Plasma. Inhibition of lipid peroxidation in Low-density lipoproteins. J Biol Chem 274, 36409-36414 (1999).

45. Rye, K. A., Hime, N. J. \& Barter, P. J. The influence of sphingomyelin on the structure and function of reconstituted high density lipoproteins. J Biol Chem 271, 4243-4250 (1996).

46. Arimoto, I., Saito, H., Kawashima, J. K., Miyajima, K. \& Handa, T. Effect of cholesterol on apolipoprotein A-I binding to lipid bilayers and emulsions. J Lipid Res 38, 287-294 (1997).

47. Arimoto, I., Saito, H., Kawashima, J., Miyajima, K. \& Handa, T. Effects of Sphingomyelin and Cholesterol on Lipoprotein Lipase-Mediated Lipolysis in Lipid Emulsions. J Lipid Res 39, 143-151 (1998).

48. Schlitt, A., et al. Serum sphingomyelin levels are related to the clearance of postprandial remnant-like particles. J Lipid Res 46, 196-200 (2005).

49. Xian-cheng, H. et al. Plasma Sphingomyelin Level as a Risk Factor for Coronary Artery Disease. Arterioscler. Thromb Vasc Biol 20, 2614-2618 (2000).

50. Vaysse, J., Pilardeau, P. \& Garnier, M. Rapid quantitative analysis of phospholipids in biological fluids after thin-layer chromatography. Clin Chim Acta 147, 183-190 (1985).

51. Agren, J. J., Kurvinen, J. P. \& Kuksis, A. Isolation of very low density lipoprotein phospholipids enriched in ethanolamine phospholipids from rats injected with Triton WR 1339. Biochim Biophys Acta 1734, 34-43 (2005).
52. Dennis, M. W., Downey, C., Brufatto, N., Nesheim, M. E., Stevenson, K., \& Toh $\mathrm{CH}$. Prothrombinase enhancement through quantitative and qualitative changes affecting very low density lipoprotein in complex with C-reactive protein. Thromb Haemost 915, 22-530 (2004).

53. Noga, A. A., Zhao, Y. \& Vance, D. E. An Unexpected Requirement for Phosphatidylethanolamine N-Methyltransferase in the Secretion of Very Low Density Lipoproteins. J Biol Chem 277, 42358-42365 (2002).

54. Parthasarathy, S., Steinbrecher, U. P., Barnett, J., Witztum, J. L. \& Steinberg D. Essential role of phospholipase A2 activity in endothelial cell-induced modification of low density lipoprotein. Proc Natl Acad Sci U S A 82, 3000-3004 (1985).

55. Portman, O. W. \& Alexander, M. Lysophosphatidylcholine concentrations and metabolism in aortic intima plus inner media: effect of nutritionally induced atherosclerosis. J Lipid Res 101, 58-65 (1969).

56. Masakazu, K., et al. Induction by Lysophosphatidylcholine, a Major Phospholipid Component of Atherogenic Lipoproteins, of Human Coronary Artery Smooth Muscle Cell Migration. Circulation 983, 53-359 (1998).

57. Noriaki, Y., et al. Lyso-phosphatidylcholine phosphorylates CREB and activates the jun2TRE site of c-jun promoter in vascular endothelial cells. FEBS LETT 457, 241-245 (1999).

58. Houtkooper, R. H. et al. Cardiolipin and monolysocardiolipin analysis in fibroblasts, lymphocytes, and tissues using high-performance liquid chromatography-mass spectrometry as a diagnostic test for Barth syndrome. Anal Biochem 387, 230-237 (2009).

59. Taguchi, R. et al. Focused lipidomics by tandem mass spectrometry. J of Chromato $B$ 823, 26-36 (2005).

60. Sommer, U., Herscovitz, H., Welty, F. K. and Costello, C. E. LC-MS-based method for the qualitative and quantitative analysis of complex lipid mixtures. J Lipid Res 47, 804-814 (2006).

61. Cole, M. J. \& Enke, C. G. Direct Determination of Phospholipid Structures in Microorganisms by Fast Atom Bombardment Triple Quadrupole Mass Spectrometry. Anal Chem 63, 1032-1038 (1991)

62. Han, X. et al. Shotgun lipidomics of cardiolipin molecular species in lipid extracts of biological samples. J Lipid Res 47, 864-879 (2006).

\section{Author contribution}

F.R. conceived, supervised and designed the study. M.D. and F.R. wrote the paper. M.D., W.K., F.H. and F.R. performed the experiments and prepared the figures. All authors; M.D., W.K., F.H., E.V. M.P. and F.R. analyzed the data and edited the manuscript.

\section{Additional information}

Supplementary Information accompanies this paper at http://www.nature.com/ scientificreports

Competing financial interests: The authors declare no competing financial interests.

License: This work is licensed under a Creative Commons

Attribution-NonCommercial-NoDerivative Works 3.0 Unported License. To view a copy of this license, visit http://creativecommons.org/licenses/by-nc-nd/3.0/

How to cite this article: Dashti, M. et al. A Phospholipidomic Analysis of All Defined Human Plasma Lipoproteins. Sci. Rep. 1, 139; DOI:10.1038/srep00139 (2011). 